\title{
The Influence of Sense of Boundary on Behavioral Competence in Intercultural Communicative Context - A Pilot Study on Overseas Students
}

\author{
Lihong Chen
}

\begin{abstract}
It is said that, by comparing with western people, most Chinese people lack sense of boundary (SoB), which significantly affects their communication and relationship with others. Similarly, SoB will influence people's intercultural communication. Therefore, the study is designed to investigate whether Chinese overseas students have weak SoB, and how SoB impacts on their behavioral competence in intercultural communicative context. A survey was constructed among Chinese overseas students in western countries and western overseas students in China. Findings reveal that the former's SoB is relatively weaker than the latter's. The results also indicate that SoB influences Chinese overseas students' competence of handling relationships, working in other cultures, and other factors of behavioral competence.
\end{abstract}

Index -Behavioral competence, competence of handling relationships, intercultural communicative competence, sense of boundary.

\section{INTRODUCTION}

Sense of boundary (SoB) is an important element of communication, and its strength and weakness will influence people's communication and relationship. Wang points out that most Chinese people lack SoB, which results in their communication problem [1]. He thinks that by comparing with western people, Chinese people do not have clear boundary in their mind and they are difficult to say no to others, and this makes them have no choice but to do something they dislike. SoB makes a difference on communication, so similarly it also influences intercultural communication. However, there is no scientific study on Chinese people's SoB either in normal communication or intercultural communication. Therefore, in the study, the author aims to investigate Chinese people's SoB in intercultural communicative context.

\section{SoB And BeHAVIORAL COMPETENCE}

\section{A. Sense of Boundary}

Boundary is a term often used in psychology, it can refer to the "limits on behavior that bring order to our lives" [2]. Also, it can reflect how our values are communicated to others and the scope of our independent core values is defined by

Manuscript received April 20, 2016; revised September 15, 2016.

L. H. Chen is with School of Foreign Languages, Guangzhou University, Guangzhou, Guangdong Province, China, 510006 (e-mail chenlhgz@163.com). boundary [3]. Ego boundary, a key concept in the theory of Paul Federn [4], refers to "a theoretical construct that explains how, in normal belief systems, people distinguish between themselves and others, between the real and the unreal" [5]. With ego boundary, one can have a clear limit between he and others, and know his right and duty and others' as well, therefore, he can protect himself and do not invade others' space [6]. As mentioned above, most Chinese people do not have SoB, which also means they lack ego boundary.

\section{B. Behavioral Competence in ICC}

To cultivate more excellent foreign language talents in China, some Chinese scholars and researchers carry out surveys on how to improve foreign language learners' intercultural communicative competence (ICC). There are different definition of ICC, and Kim (1991, qtd in Peng, 2007) points out that ICC refers to the competence that one can carry out successful communication in different cultural environment [7]. Byram (1997) believes that ICC model should includes attitudes, knowledge, skills and critical cultural awareness [8]. Based on this model, some researchers divide ICC into 3 dimension, namely cognitive competence, affective competence and behavioral competence (Chen \& Starosta, 2000; Spencer-Oatey \& Franklin, 2009; Zhang et al, 2012; all qtd in Yu, 2012) [9]. Cognitive competence refers to common and specific cultural knowledge and knowledge of politics, economics, geography, history, humanity, religion, customs etc, which communicators need; affective competence contains sensitivity of cultural differences, empathy of different cultures, keen appreciation of self culture and respect to others' culture; and behavioral competence refers to different competences of communicator, including verbal language, non-verbal language, flexibility, handling relationships, psychological adjustment, environment adaption and working in other cultures, etc. (Hu, 2013:5, the author's translation) [10].

There are many studies on ICC, and Peng (2007a:173) believes that the study on ICC should start from communicative behavior, and the factors that influence intercultural communicative behavior [7]. As mentioned above, SoB influences Chinese people's communication, likewise, it will influence intercultural communication. A number of factors impact on intercultural communicative behavior, but up to now, no study indicates SoB have noticeable effect on behaviors in intercultural communicative context. Therefore, in this study, the author will explore SoB's influence on intercultural communicative behavior. 


\section{THE STUDY}

\section{A. The Participants}

To ensure the intercultural communicative context for the study, overseas students were chosen as the participants in the study, and they were divided into 2 groups. Group 1 is 39 Chinese overseas students in different countries, and they are having undergraduate or postgraduate study at the moment. Group 2 is 27 foreign students who learn Chinese in China, most of them are undergraduate students of different majors and they choose to learn Chinese for one or two years. The age of Group 1 ranges from 20-26, the foreign countries they study in mainly cover America, Australia, Canada and some European countries, and they have been in the foreign cultures for 1-4 years. The age of Group 2 ranges from 18-30, and they are mainly from American, Canada, Australia and some European countries, and they have been in China for 1-2 years.

\section{B. Research Questions}

In order to survey the influence of SoB on behavioral competence in intercultural communicative context, two research questions are raised: 1) How is Chinese overseas students' SoB? (Whether Chinese overseas students' SoB is weaker than western students who learn Chinese in China?) 2) How does SoB influences Chinese overseas students' behavioral competence?

\section{Instruments and Data Collection}

Questionnaire and interview were applied in the study. There were 2 questionnaires. Questionnaire 1 was designed to investigate overseas students' sense of boundary and it was handed out to all the participants. As mentioned above, there is no similar research about $\mathrm{SoB}$ and behavioral competence, so the author designed the questionnaire according to some statements about SoB in some articles of Part 2 above, and also some ideas from Cloud and Townsend (1999) [11]. The first part of the questionnaire is the basic information including gender, age, origin country, overseas studies country, duration. The second part is to investigate overseas students' SoB, mainly focus on the relationship with teachers and friends (also including classmates and flat-mates), which represents the main relation of overseas students in foreign countries. Since "friend" can be applied to a very wide range of relationship, "friend" in this study mainly focus on the campus context, which include classmates, flat-mates and some other people they get to know in their campus. This means that the "friend" in the study is the people they get to know in the foreign cultures. All these friends may come from different countries including China, and in order to make a close relation with intercultural communicative context and compare with western people, friends here are limited to the people of western countries. Twenty descriptions about SoB were shown on the questionnaire, and the descriptions include 3 perspectives, others' duty and one's duty, and tendency of saying no to others. Likert scale was used to collect the data, from 1 to 5, which ranges from weak to strong SoB. At the end of Questionnaire 1, there is a question about whether the participants are willing to accept a follow-up interview or not.

Questionnaire 2 was designed to analyze Chinese overseas students' average degree of the elements of behavioral competences. The questionnaire was designed according to the 7 components of behavioral competences, and it was done by the 11 Chinese overseas students who were willing to be interviewed.

Interviews were employed to further survey the influence of SoB on intercultural communicative behavior. Among 39 Chinese overseas students who completed the questionnaires, 11 of them were willing to be interviewed. The interview was done through Wechat. It was consist of 2 parts, one was based on the results of questionnaire, and the other was to investigate the influence of SoB on behavioral competence. In order to make the interviewees understand and express easily, all the interviews were done in Chinese, and the following English transcript was translated by the author.

The data was mainly collected via the Internet. A link of the questionnaire was sent out to some known Chinese overseas students, and they were asked to send the questionnaire to some more students, and finally 39 questionnaires were returned. For the foreign students, electronic versions of questionnaire was sent out, and 27 finished questionnaires were received.

\section{RESULTS AND DISCUSSION}

\section{A. Overseas Students' SoB}

From the data analysis of questionnaire, it can be seen that Chinese overseas students' average SoB is not very high $(\mathrm{M}=2.23)$, while that of overseas students from western countries is relatively higher $(M=3.91)$. To some extent, the result can indicate that Chinese overseas students have weaker SoB than western overseas students. In the main relationship with teachers and friends, Chinese overseas students' SoB with teachers is not very high as well $(M=2.62)$, and so is the average with friends $(M=2.14)$. On the contrary, western overseas students' SoB with teachers $(M=4.2)$ and friends $(m=3.9)$ is both stronger than that of Chinese overseas students. Also, as Wang mentions above, Chinese people do not have strong tendency to say not to others, so do the Chinese overseas students (Table I).

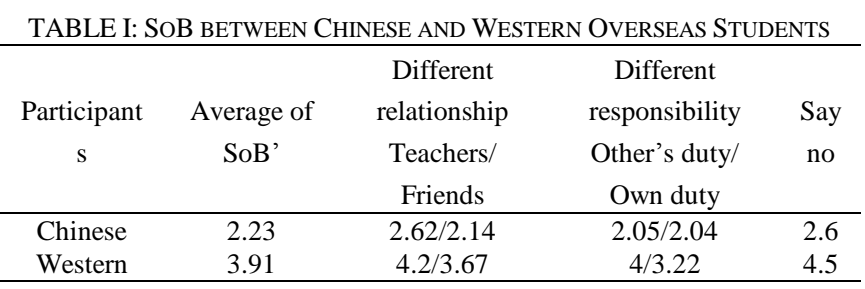

After the author finished the analysis of the data and got the result, the author had a follow-up interview with the 11 overseas students who indicates that they are willing to accept the interview. By doing so, the author aims to find out the reasons of the above results. First, the author explained SoB to the 11 interviewees $(\mathrm{C} 1-\mathrm{C} 11)$, told them the overall average of Chinese overseas students and that of western students, and asked them to have a reflection about their own SoB. They all think they have weak SoB. Most of them said they never noticed their SoB, and they simply did what they 
normally did in China. They think what they do is very normal in the Chinese context, most Chinese people will do the same as them.

In the intercultural communicative context, two main relationships were investigated, namely teachers and friends. For the Chinese overseas students, they believe that it is very common for students to do something for teachers or friends which are the main relationship of campus. For example, C3 said:

In China, it is very common for students to do something for our teachers, sometime even our teachers do not ask us to do. For example, once, other 2 classmates and I had a buffet with our head teacher, and after we took our seats, it was very natural for us to ask our head teacher what he would like to eat, and we then took some food for him...He is young, about 40 ... It's not about the age, we tend to regard teachers as our elders, and we should respect them, so it is very common for students to do something for teachers in Chinese context.

Friends are also the same, the interviewees believe that friend in need is friend indeed. A typical situation is offered to all the interviewees: "Your good friend breaks up with her boyfriend and feels very upset. She would like to take a one-day trip to relax, and asks you to go with her. You have not finished your project, and tomorrow is the deadline. Will you go with her?" Eight of the 11 interviewees decided they would go with the friend. C8 said:

Friends are very important for us, so I think I should accompany with her when she is upset...I know, I have the assignment to finish, but she needs me, otherwise she won't ask me to go with her...I will have to finish my assignment after coming back, even though I have to stay up late.

All of these can indicate that the interviewees do not have a clear limit between themselves, teachers and friends. With strong SoB, one can have clear idea about his duty and right. From the interview, it can be found that the interviewees do not have a clear mind about their and others' duty. For example, it is not C3'S duty to take food for his head teacher when having buffet. Similarly, C8 does not have the duty to accompany her unhappy good friend. SoB can bring orders to our lives, if one does not know his duty and other's duty, the order will be broken. For example, C10 mentioned:

When I was in China, sometimes my flat-mates forgot to throw the rubbish, and I would do for them. My parents always tell me I should help others if I can ... yes, I know it's not my duty to throw the rubbish, but they just forget or they are too busy, sometimes, I think it is not a big deal, and I just do it.

Without strong SoB, Chinese people tend to do something that does not belong to their duty, and by doing so, some orders of lives of broken, and this also happens to the interviewed Chinese overseas students.

Saying no is greatly difficult for most Chinese people, they choose to say yes even though they are reluctant. This is the most common in Chinese family. In China, most children have to obey to their parents, even though sometimes their parents may be wrong. For example, some parents will force their child to choose the major they like when entering university, because they think their decision is right, the major is good, and the future will be bright after taking the major, however, their child's will is totally ignored. This always happens, and another typical example is about marriage. Some parents think it is not good for their child to get married with his/her beloved, and they will try their effort to stop them getting married. Therefore, it is hard for children to say no to their parents, and this makes them also difficult to reject other people. C6 offered a common example:

It is really difficult for me to reject other people in China, for example, my friend ask me to see a movie with him, and actually I don't like the movie, but I always feel difficult to say no, and I think it's not a big thing to see the unlike movie, so I finally go with him. And something like this always happens to me, and I find some of my friends also have the same situation. I think it's kind of habit, in my family, I seldom say no to my parents and other elders, and this makes me do the same with my friends... I know I have the problem, but it's really hard for me to say no to other people, even though I am not willing.

To sum up, most of the interviewees' SoB are influenced by their parents, family, living environment, and what the Chinese people with weak SoB do also have an impact on them.

\section{B. The Influence of SoB on Behavioral Competence}

In Questionnaire 2, the influence of SoB on Chinese overseas students' behavioral competence was analyzed. In this part, the degree of influence is calculated with 10 points, which 1 means least influence and 10 represents most influence, and the final result is shown in Table II.

TABLE II: AVERAGE DEgREE Of SoB's INFLUENCE ON BEHAVIORAL

\begin{tabular}{cc}
\multicolumn{2}{c}{ COMPETENCE } \\
\hline Behavioral competence & Average degree $(\mathrm{M}=1-10)$ \\
\hline Verbal language & 6.85 \\
Non-verbal language & 3.04 \\
Flexibility & 5.16 \\
Handling relationships & 9.23 \\
Psychological adjustment & 7.72 \\
Environment adaption & 8.17 \\
Working in other cultures & 8.51 \\
\hline
\end{tabular}

From the data, it can be found that SoB influences the competence of handling relationship $(\mathrm{M}=9.23)$ most. Working in other cultures( $\mathrm{M}=8.51)$, environment adaption $(\mathrm{M}=8.17)$ comes second and third. The least influence is non-verbal language.

Based on the above results, the author carried out the second part of interview, which mainly focuses on the question of "How does SoB influence different elements of behavioral competence?"

First is the influence of handling relationship. Through interpersonal relationship, people are connected which varies from temporary to long-standing, and it happens through the interaction of different people in social and cultural context (Ji, 2012) [12]. Therefore, it is a very important factor in 
communication, so most interviewees regards handling relationships as essential. They think SoB do influence how they handle relationships, as they do not know clearly about the limit on their behavior. For example, as mentioned above, in China, teachers are elders for students, so students believe it is their duty to do something for teachers, and they do exactly the same as they do in the Chinese context. $\mathrm{C} 1$ said:

When I see my supervisor is very busy, and as his student, I think I should help him to reduce the burden. Once, I saw his office was in a mess, and I offered my help to clean it. My supervisor was so surprised and he rejected my kind help. I was upset and don't know why he rejected me, it is very common in China if I help my tutor to clean the office. So, at the very beginning when I came to the UK, I had no idea how I should keep in touch with my tutors or supervisor, they are so cool, and I don't have many opportunities to see them. When I have the chance, I then would like to do something them.

What happens to $\mathrm{C} 1$ is called automatic transfer, this is one kind of cultural barrier. When one moves to a new foreign culture, he tends to assume something should be similar with that in Chinese culture. In this case, for example, the student wanted to help the teacher clean the office. After the assuming similarity, he transferred the behavior automatically and offered the help to clean the office. However, in the western culture, it is not common, and teachers have a very clear limit with the relationship of teacher and students, and they will not ask students to something that is not their responsibility. C11 also had the same trouble, he thinks, in China, teachers and students can be very closed, but in the foreign culture, it is different. He and his supervisor are simply student and teacher. For the Chinese overseas students with weak SoB, it is hard to handling the relationship of teacher and student in the foreign country as it is different from Chinese context, and this always brings culture shock for the Chinese overseas students.

For friends, the interviewees also had some problems. When moved to the foreign cultures, Chinese overseas students make some new friends, such as classmates, flat-mates, friends of the university. Friendship in some western countries are different from Chinese context, and people have different way treating friends. Some interviewees think they should build up a good relationship with classmates, flat-mates and other friends in the foreign countries, therefore, they believe they should help each other, and the others also have the duty to do the same.

In China, people are hospitable to their friends, and it is very common to treat friends a dinner even they are new friends. While in western countries, when having dinner, people like to pay separately for the own bill, and most Chinese people think it is not unusual to treat friends in this way, this is what C4 complained:

I am so excited to makes some new friends here, and at the very beginning, I invited some new friends to have dinner, and I said I would pay for the meal, and nobody took my offer, I felt really confused, as in China, that's so normal to treat friends with meals...To be honest, I think it's not very hospitable, you know, in China, this normally won 't happen, I told my parents about it and they think it's not polite... another thing I feel strange is that once one of my classmates invited us to have a party in her house, and every one was required to bring a dish to her house. I was shocked and confused again. Isn't it the host's duty to make some food for us since she invited us? Also, I told my parents about it, and they believed that won't happen in China.

To be concluded, Chinese overseas' SoB has an great impact on their handling relationship, which may result in culture shock and sometimes even some misunderstanding.

Second is working in other cultures $(\mathrm{M}=8.51)$. As mentioned above, moving to a new foreign culture, overseas students experience culture shock and their SoB also has impact in this perspective. C2 showed his ideas:

My SoB is influenced by Chinese culture, and because I don't have a strong SoB, I always do things as what I do in China, and sometimes this brings me barrier to work in this foreign culture.

Third is environment adaption $(\mathrm{M}=8.17)$ and fourth is psychological adjustment $(M=7.72)$. According to most of the interviewees, SoB influences overseas students' environment adaption and psychological adjustment, especially when they handle different relationship, and when they have some problems in understanding the new culture. Therefore, it may become a long period for some students to get adjusted psychologically. Fifth is verbal language $(M=6.85)$. Verbal language plays a vital role in communication and also intercultural communication. SoB sometimes influences the Chinese overseas students' verbal language. For example, they do not have a very clear limit of own duty, and they may say something wrong.

Flexibility is also influenced by SoB. Since their SoB is impacted by Chinese culture deeply, Chinese overseas students sometimes can not change their behavior or language in a flexible way. According to Stella Ting-Toomey (1999:120, qtd in Brown, 2011) [13], nonverbal communication is "omnipresent throughout a culture", and more than 65 percent of communication is done by nonverbal language. In the study, SoB has the least impact on nonverbal language of behavioral competence. Some interviewees indicated that they knew something about nonverbal language in different cultures, $\mathrm{C} 9$ pointed out that:

Before I came to the USA, I tried to learn some taboos about nonverbal language, so I don't have many problems in using it when I communicate with others. And I think whether my $S o B$ is weak or strong, my nonverbal language won't be influenced a lot.

To sum up, SoB influences Chinese overseas students' behavioral competence differently, and most of the influences origins from Chinese culture and their habits.

\section{Suggestions}

From the analysis and discussion, it can be found that most 
of the Chinese overseas students have weak SoB, which influences their behavioral competence in the intercultural communicative context. The influence brings some misunderstanding and difficulty for their intercultural communication, therefore, it is necessary to discuss some suggestions.

First, the Chinese overseas students should know more about their weak SoB, analyze their problematic behaviors which are influenced by SoB. They also need to make a clear cut between their duty and other's. Especially in the perspective of saying no to others, the Chinese overseas students should not consider "face" greatly and learn to reject other people's requirement when necessary. Second, the influence of SoB on behavioral competence is resulted from some cultural differences, so Chinese overseas students need to know more about intercultural communication and get rid of cultural barriers.

\section{CONCLUSION}

To find out Chinese overseas students' SoB and the influence on their behavioral competence, a survey was constructed among Chinese overseas students in western countries and western overseas students in China. Findings reveal that the former's SoB is relatively weaker than the latter's. The results also indicates that SoB has a great influence on Chinese overseas students' behavioral competence of handling relationships, working in other cultures, and other factors differently.

This is a small-scale pilot study, and there are some limitations. First, more references about SoB and behavioral competence are needed, as there are few academic references in the study. Second, there are only 39 participants of Chinese overseas students and 27 foreign students who learn Chinese in China. The number of the participants is not big enough, a large number of participants is needed for the future study. Also, the duration the participants have been in the foreign cultures is different, which may influence the data. Therefore, it is better to choose some participants with similar duration. Third, for the interview part, there are only Chinese students, so foreign students should be found to be interviewees in the further study. Fourth, there is no related questionnaire about SoB, the questionnaire designed by the author, so a more systematic and comprehensive questionnaire is required. Last, further study needs to be carried out to find out why Chinese overseas students have weaker SoB deeply, which can offer some more implication for them to improve their behavioral competence in intercultural communicative context. Also, due to limit data and references, the analysis of the influences of $\mathrm{SoB}$ on behavioral competence is not scientific enough, and some more evidence or references are needed.

\section{REFERENCES}

[1] Z. H. Wang. (2016). Most Chinese Lack Sense of Boundary. [Online]. Available: http://www.xinli001.com/info/100310476

[2] Tips for Setting Limits and Boundaries. [Online]. Available: http://susangaddis.net/2013/01/setting-limits-and-boundaries/

[3] R. S. Johnson. (2014). Setting Boundaries and Setting Limits. [Online]. Available: http://bpdfamily.com/content/setting-boundaries

[4] International Dictionary of Psychoanalysis, Ego Boundaries. (2005). [Online]. http://www.encyclopedia.com/doc/1G2-3435300413.html

[5] Bobbies. (2015). What is An Ego Boundary? [Online]. Available: http://www.themedicalquestions.com/healths/what-is-an-ego-boundar y.html

[6] Ego Boundary. (2014). [Online]. Available: https://www.douban.com/note/356179621/

[7] S. Y. Peng, "Intercultural sensitivity: A comparison between English majors and Non-English majors," Journal of Ningxia University, Humanities and Social Sciences Edition, vol. 29, no. 1, pp. 171-176, 2007a.

[8] M. Byram, Teaching and Assessing Intercultural Communicative Competence, Shanghai: Shanghai Foreign Language Education Press (by arrangement with Multilingual Matters/Channel View Publication Ltd, edition of 1997), 2014, pp. 31-43.

[9] W. Q. Yu, “An empirical research on foreign learners' intercultural competence: Sensitivity and effectiveness," Chinese Teaching in the World, vol. 26, no. 5, pp. 551-559, 2012.

[10] W. Z. Hu, "The cultivation of intercultural communication competence in foreign language teaching," Foreign Language World, no. 6, pp. 2-8, 2013.

[11] H. Cloud and J. Townsend, Boundary, Henry Cloud and John Townsend Grand Rapids, Michigan, 49530, 1999, D. A. Cai, Trans. Shenzhen: Haitian Press, 2014, ch. 1 \& 2.

[12] Y. H. Ji, A Practical Course in Intercultural Communication, Shanghai: Shanghai Foreign Language Education Press, 2012, p. 103.

[13] H. D. Brown, Tips for Teaching Culture: Practical Approaches to Intercultural Communication, Qinghua University Press, 2011.

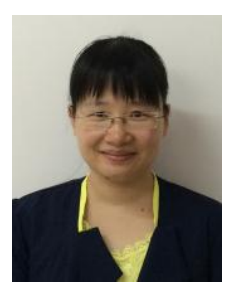

Lihong Chen was born in the city of Shantou, Guangdong province, China on June 25, 1979. The author got BA degree from Guangzhou University in China, majored in English education in 2002, and two MA degrees from University of York in 2005 and University of Bristol in 2006 in the UK, majored in educational studies and psychological education.

She works as a teacher in University of Guangzhou in Guangzhou, China now. She has published some Chinese articles about intercultural communication, English education and education of pre-service teachers. Her current and previous research interests are on intercultural communication, second aqusition and education of pre-service teachers.

Ms. Chen is a member of China Association for Intercultural Communication. 